\title{
Are you passionate about health and social care research?
}

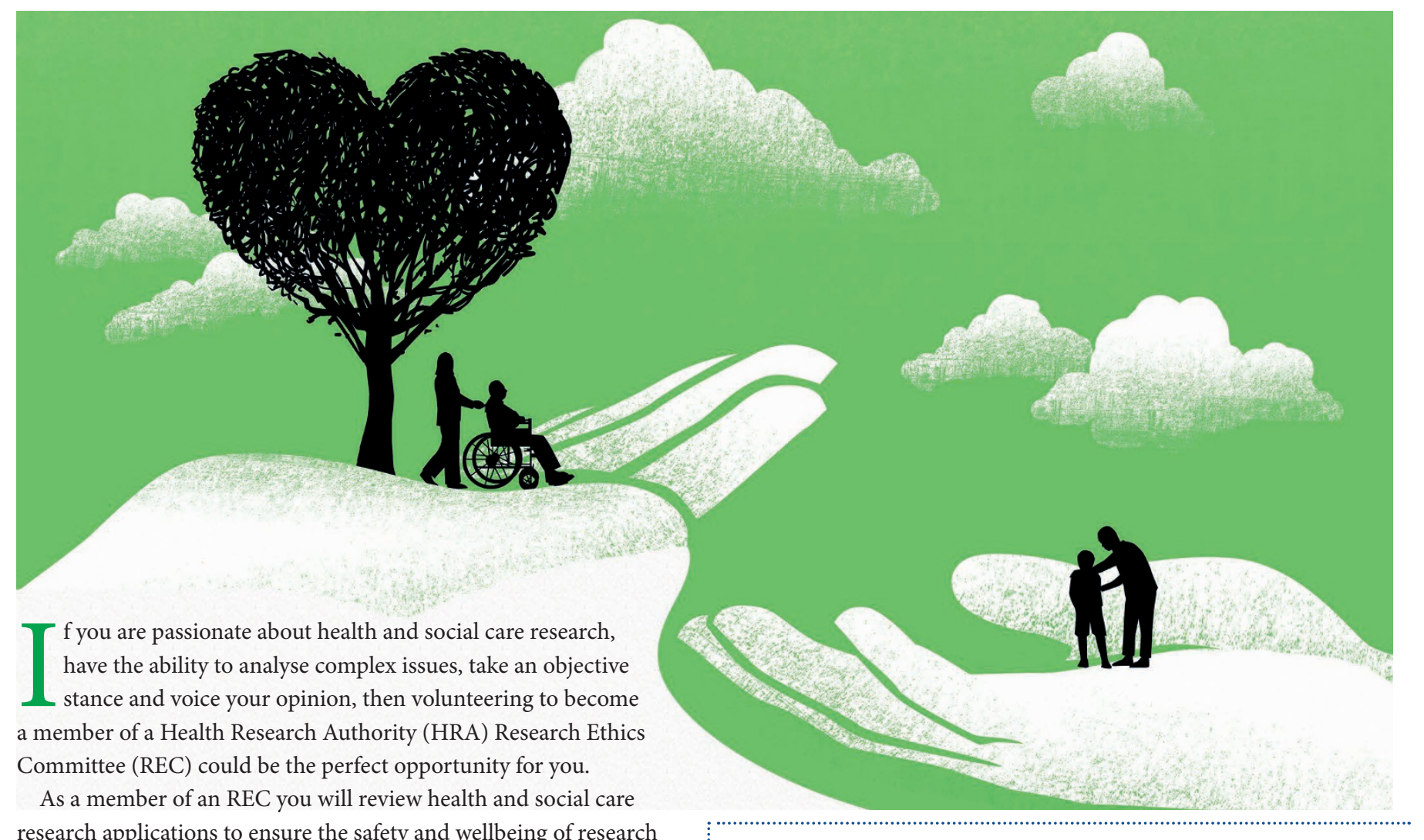
research applications to ensure the safety and wellbeing of research participants and the public.

Training will be provided and you will need to commit to attend at least six full REC meetings per year plus some additional sub-committee business in between meetings. There are 66 committees across England, so we will be able find you a meeting that is local to you. Travel will be reimbursed.

The HRA is keen to receive applications from people from a variety of backgrounds and experiences who have an interest in health research and ethics.

As an REC member you will gain: increased knowledge in research methodology and statistics; a better understanding of research ethics and relevant legislation; committee skills; and access to HRA member training events.

You will also have the opportunity to train for the role of a REC Chair/Vice Chair after one year of membership.

Further information on committee membership is available at: www.hra.nhs.uk/about-us/committees-and-services/res-and-recs/ become-rec-member//. Applications are on a rolling basis so there is no specific deadline.

For an informal discussion contact Louise Braley on 02079722587 or email Louise.Braley@nhs.net.

\section{Notice of deaths}

It is with sadness that we note the recent deaths of Albert $\mathrm{E}$.

L. Adeline who died at the age of 103 on 11 January 2018 and Jonathan Davies who died suddenly aged 56 on 17 Janurary 2018.

Our sympathies go to families, friends and colleagues. 